\title{
Cornering kids with coupons and Camel Cash
}

\begin{abstract}
"I collect the Marlboro coupons and it takes a million just to get a $T$ shirt. What am I supposed to do, quit? Well, I heard it wasn't that bad anyway." - Michael Doo, of New York City, commenting on the Philip Morris recall of cigarettes contaminated with methyl isothiocyanate $(M I T C) .^{1}$
\end{abstract}

In 1993 the tobacco industry in the United States spent $\$ 6$ billion to advertise and promote cigarettes. As detailed elsewhere in this issue of Tobacco Control, ${ }^{2}$ these expenditures have increased more than fourfold since 1975 in real terms (that is, after adjustment for inflation). A striking trend is that the proportion of this spending allocated to traditional forms of printed advertising magazines, newspapers, outdoor, transit, and point-of-sale - has steadily declined, from $70 \%$ in 1980 to $16 \%$ in 1993. The relative decline in print advertising reflects an industry shift in marketing strategies to place greater emphasis on promotional methods such as free sampling, coupons, value-added offers (for example, buy two, get one free), promotional payments to retailers, and sponsorship of art, sports, and cultural events. The proportion of the industry's marketing expenditures devoted to these types of promotions has increased from $30 \%$ in 1980 to $84 \%$ in 1993.

In recent years, proof-of-purchase redemption programmes (also called "cigarette continuity programmes" or "frequent smoker programmes") have become a favourite promotional gimmick used by cigarette companies. As chronicled by Sumner and Dillman in this issue of the journal, ${ }^{3}$ we now have seen Camel Cash catalogues; Winston Weekend and Winston Select Weekends calendars; the Marlboro Adventure Team, Country Store, and Marlboro Gear catalogues; American Tobacco Company's American Value Series catalogue; the Merit Awards catalogue; Carlton Vacation Cash; Raleigh-Belair 72 catalogue; Virginia Slims V Wear; Vantage Inner Circle; and the Winston Select Trading Company. These programmes usually offer theme oriented merchandise "branded" with cigarette emblems, in exchange for proofs-of-purchase (for example, Camel Cash, Marlboro Miles, or bar coded universal product codes). Sumner and Dillman conclude that these programmes "provide modest real economic incentives for smoking, and probably create or reinforce other incentives to smoke."

The quotation appearing above from a New York City smoker demonstrates the strength of the grip with which these coupon schemes control many smokers. Continuing to collect Marlboro coupons was clearly more important to him than quitting smoking, and also more important than switching brands in the face of a national recall of Marlboro (and other Philip Morris brands) due to chemical contamination of their cigarette filters. ${ }^{4,5}$

Although the age of the New York City smoker was not disclosed in the article in which he was quoted, ${ }^{1}$ the greatest concern about cigarette continuity programmes is that they have special appeal to youth. Two other papers published in this issue of Tobacco Control provide evidence that the programmes do exactly that. ${ }^{6,7}$

Richards and colleagues ${ }^{6}$ surveyed 616 students $14-18$ years old in two high schools - one in Massachusetts and one in New Mexico. Thirty nine percent of the students had heard of Camel Cash, including $69 \%$ of current smokers. Nine percent had collected Camel Cash, including $25 \%$ of current smokers. Thirty two $(5.2 \%)$ of the students had purchased Camel cigarettes in order to get Camel Cash.

Although the study by Richards et al was conducted in only two high schools in two different states, other studies have reported similar findings. In a study of ninth graders (14-15 years old) in Erie County, New York, $48 \%$ of occasional smokers and $28 \%$ of non-smokers reported owning branded clothing. ${ }^{8}$ Equally worrisome findings, based on national survey data, are reported in this issue by Coeytaux and colleagues. ${ }^{7}$ These investigators conducted a telephone survey of a nationally representative sample of 1047 minors $12-17$ years of age. They found that $35 \%$ of the minors reported either having owned a tobacco promotion item, or having collected coupons such as Camel Cash or Marlboro Miles, or having possessed a catalogue distributed by a tobacco company that depicted promotional items obtainable through coupon redemption. Extrapolated to the total US population of the same age, this figure corresponds to an estimated 7.4 million youths. Eleven percent of the minors owned a product that promoted a tobacco brand or was distributed by a tobacco company; an estimated $20 \%$ of these promotional items were obtained through coupon redemption, and an additional $12 \%$ were obtained directly through the purchase of a tobacco product. A Gallup poll found even higher ownership of tobacco promotional items - about half of adolescent smokers and one quarter of non-smokers owned at least one of these items. ${ }^{9}$

Richards et al and Coeytaux et al recommend the prohibition of tobacco promotional items. After their papers were submitted for publication in Tobacco Control, President Clinton and the US Food and Drug Administration (FDA) announced proposed rules that would significantly curb tobacco advertising and promotion (see pages 287-297 in this issue). The FDA proposal "would prohibit all proof of purchase sales or gifts of non-tobacco items as well as all contests, lotteries, or games of chance that are linked to the purchase of, or in consideration for, the purchase of a tobacco product." 10

As the FDA's proposal moves forward in the regulatory process and in the courts, where it has been challenged by tobacco and advertising interests, offensive and destructive tobacco promotions continue unabated. In my own state I happened across a billboard advertising Marlboro Gear, near a "Toys " Us" store and a "Chuck E Cheese Pizza" playland (see figure)- both of which cater to children. And in early September - less than a month after the President announced the FDA proposal-Philip Morris trumpeted the introduction of Marlboro Unlimited, a promotional programme offering 2000 sweepstakes winners and their guests the opportunity to explore the American West ("Marlboro Country") aboard "an extraordinary, one-of-a-kind, custom-built train that's a third of a mile long". ${ }^{11}$ The train will be painted red and white like Marlboro's packaging, and the name Marlboro will be painted on the side of the train. ${ }^{12}$

According to Philip Morris' announcement, "Winners will have the opportunity to take unique side trips when they leave the train and explore the American West via 

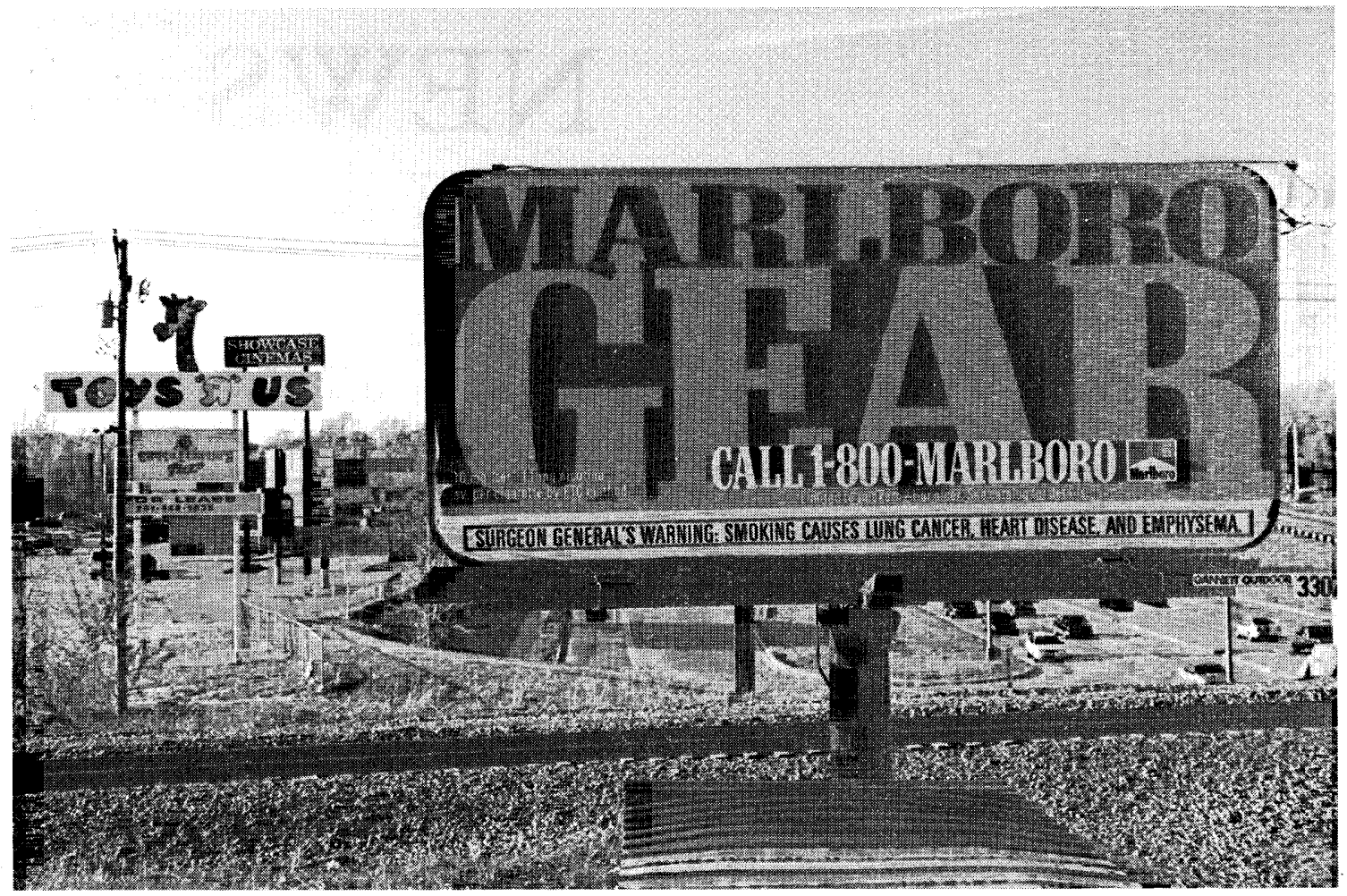

A billboard promoting Marlboro Gear near a "Toys ' $Я$ ' Us" store and a "Chuck E Cheese Pizza" playland, both of which cater to children (Dearborn, Michigan, USA).

horseback riding, white-water rafting, biking, hiking, fishing, hot-air ballooning and sight-seeing. In addition, premiere country music artists and rodeo stars will deliver exceptional performances exclusively for Marlboro guests." 11

The sweepstakes period will run from 1 November 1995 to 30 April 1996, and will be accompanied by 30 new items in the Marlboro Unlimited Gear catalogue. Promotions for the campaign will include 12-page inserts in magazines such as Sports Illustrated, People, and GQ. ${ }^{13}$ Those who aren't lucky enough to win a ride on the train "can experience a bit of the adventure of The Train and The Trip by collecting Marlboro Unlimited miles for the new gear items." 11

Philip Morris claimed that the Marlboro Unlimited sweepstakes, train ride, and gear would be available only to adult smokers. Congressman Henry Waxman of California retorted that " a fun-filled train ride with a hot tub, movie theater and dancing would sound like a kid's dream come true." 12 And Michael Pertschuk, codirector of the Advocacy Institute, added, "Part of what Philip Morris is doing with its money is retarding the social revolution against smoking and targeting populations that are still open to the romance of the notion of a cigarette. And that group is the youth market."'13

Cigarette continuity programmes are also springing up in other countries. In the United Kingdom, for example, Benson and Hedges offers 10 "gratis points" for every 20 cigarettes purchased, which can be redeemed for gifts from the respected Littlewoods stores group. ${ }^{14}$ In countries where these promotions are still legally permissible, tobacco control advocates must take steps to prevent the sort of explosion of cigarette continuity programmes that has plagued the United States.

The FDA has the opportunity to end these shananigans in the USA. The studies published in this issue of Tobacco Control $^{3,6,7}$ provide further evidence to support strong FDA action to counter this "pediatric disease". ${ }^{15}$

\section{Editor}

RONALD M DAVIS

1 Powe S. Cigarette recall doesn't faze New York smokers - too much. New York Daily News 1995; 1 June.

2 Cigarette advertising and promotion in the United States, 1993. A report of the Federal Trade Commission. Tobacco Control 1995; 4: 310-313.

3 Sumner W, Dillman DG. A fist full of coupons: Cigarette continuity programmes. Tobacco Control 1995; 4: 245-252.

4 Boyd A. Warning: apart from dying, you may feel dizzy. Tobacco Control 1995; 4: 215-217.

5 The Philip Morris recall. Tobacco Control 1995; 4: 282-286.

6 Richards JW, DiFranza JR, Fletcher C, Fischer PM. RJ Reynolds' "Camel Cash": Another way to reach kids. Tobacco Control 1995; 4: 258-260.

7 Coeytaux RR, Altman DG. Tobacco promotions in the hands of youth Tobacco Control 1995; 4: 253-257.

8 Survey of alcohol, tobacco and drug use among ninth grade students in Eri County, 1992. Buffalo, New York: Roswell Park Cancer Institute, 1993.

9 Bezilla R. Teen-age attitudes and behavior concerning tobacco. Princeton, New Jersey: Gallup International Institute, September 1992.

10 US Food and Drug Administration. Proposed rule: regulations restricting the sale and distribution of cigarettes and smokeless tobacco products to protect children and adolescents. Federal Register 1995; 60 (155): protect child

11 Philip Morris USA. Marlboro Unlimited sweepstakes brings back the magic of railroad travel and rediscovers the West along the way. Business Wire, 7 September 1995.

12 Goldman K. Philip Morris promotions keep on rolling. Wall Street fournal 1995; 7 September: B6.

13 Philip Morris kicks off Marlboro Unlimited promotion. Tobacco Reporte 1995; October: 69.

14 Carnall D. BMA criticises gift catalogue. BMF 1995; 310: 1223.

15 Kessler DA. Remarks to the Samuel Rubin Program, Columbia University School of Law, New York, New York, 8 March 1995 (written text). 